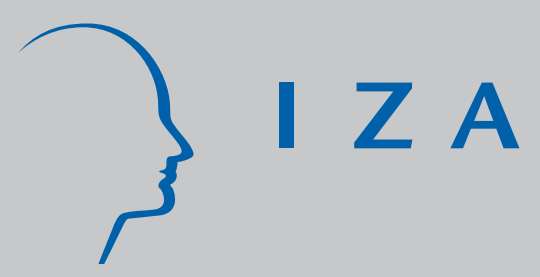

IZA DP No. 3604

Happiness Dynamics with Quarterly Life Event Data

Paul Frijters

David W. J ohnston

Michael A. Shields

July 2008 


\title{
Happiness Dynamics with Quarterly Life Event Data
}

\author{
Paul Frijters \\ Queensland University of Technology and \\ RSSS, Australian National University \\ David W. Johnston \\ University of Melbourne \\ Michael A. Shields \\ University of Melbourne \\ and IZA
}
Discussion Paper No. 3604
July 2008

IZA

P.O. Box 7240

53072 Bonn

Germany

Phone: +49-228-3894-0

Fax: +49-228-3894-180

E-mail: iza@iza.org

Any opinions expressed here are those of the author(s) and not those of IZA. Research published in this series may include views on policy, but the institute itself takes no institutional policy positions.

The Institute for the Study of Labor (IZA) in Bonn is a local and virtual international research center and a place of communication between science, politics and business. IZA is an independent nonprofit organization supported by Deutsche Post World Net. The center is associated with the University of Bonn and offers a stimulating research environment through its international network, workshops and conferences, data service, project support, research visits and doctoral program. IZA engages in (i) original and internationally competitive research in all fields of labor economics, (ii) development of policy concepts, and (iii) dissemination of research results and concepts to the interested public.

IZA Discussion Papers often represent preliminary work and are circulated to encourage discussion. Citation of such a paper should account for its provisional character. A revised version may be available directly from the author. 
IZA Discussion Paper No. 3604

July 2008

\section{ABSTRACT}

\section{Happiness Dynamics with Quarterly Life Event Data*}

This paper addresses the question of when and to what extent individuals are affected by major positive and negative life events, including changes in financial situation, marital status, death of child or spouse and being a victim of crime. The key advantage of our data is that we are able to identify these events on a quarterly basis rather than on the yearly basis used by previous studies. We find evidence that life events are not randomly distributed, that individuals to a large extent anticipate major events and that they quickly adapt. These effects have important implications for the calculation of monetary values needed to compensate individuals for life events such as crime or death of spouse. We find that our new valuation methodology that incorporates these dynamic factors produces considerably smaller compensation valuations than those calculated using the standard approach.

JEL Classification: $\quad 10$

Keywords: life satisfaction, life events, adaptation, compensation

Corresponding author:

Michael A. Shields

Department of Economics

University of Melbourne

Australia 3010

E-mail: mshields@unimelb.edu.au

\footnotetext{
* We would like to thank Andrew Oswald and John Freebairn for useful comments and suggestions. The usual disclaimer applies.
} 


\section{Introduction}

There has been a torrent of studies in the economic literature over the last five years that have tested the importance of major life events such as marriage, divorce, disability, unemployment and financial shocks for life satisfaction or happiness, and the phenomenon of adaptation to such events. A general survey of this issue can be found in Clark et al. (2008). In this paper we contribute to this growing literature by developing a formal model that defines selection, anticipation and adaptation effects, and importantly use more detailed data on the timing of life events. In particular, we use information about the actual quarter of the event rather than the year of the event as is common in the literature. We then draw out the policy implications by calculating the income equivalent value of these life events for which we introduce a new method that utilises information on major financial events and takes into account dynamic effects.

Various theoretical studies rationalise the existence of adaptation in an evolutionary context and explore its implications for utilitarian accounting (see Menzel et al., 2002; Graham and Oswald, 2005; Rayo and Becker, 2007; and Dolan and Kahneman, 2008). The emerging empirical literature on the impact of life events on happiness has also mainly focussed on adaptation. Life events that have been studied include unemployment (Lucas et al., 2004; Clark, 2006), marriage and divorce (Lucas and Clark, 2006; Zimmerman and Easterlin, 2006; Oswald and Gardner, 2006); income (Di Tella et al., 2005; Kuhn et al., 2008); and disability (Oswald and Powdthavee, 2008). A recent study that does examine both anticipation and adaptation is Clark et al. (2008). Using data from the German Socio-Economic Panel (GSOEP), Clark et al. (2008) define six life events (unemployment, marriage, divorce, widowhood, birth of child, and layoff) by observing year-to-year changes in individuals' answers to survey questions. Estimates from fixed-effects regressions, estimated separately for each life event, show strong evidence of anticipation and adaptation effects. ${ }^{1}$

A limitation of the existing empirical literature, however, is that the timing of life events is often poorly measured i.e. events are simply defined as occurring 'sometime in the last 12 months'. Another difficulty is that one life event is almost invariably related to a set of concurring life events. For instance, divorce is often accompanied by a fall in income as well as a shock to housing arrangements, making it hard to draw causal inferences if we only focuses on one particular life event. By using high-quality data from six waves of the Household, Income and Labour Dynamics in Australia survey (HILDA), we can tackle both problems at the same time. HILDA asks individuals to detail the quarter in which a life event occurred, which allows us to estimate anticipation and adaptation effects pertaining to the quarter in which it occurred. This will be particularly useful for investigating events that people adapt to within a relatively short period. In addition, HILDA has a large array of questions that allow us to simultaneously look at many events that are correlated with

\footnotetext{
${ }^{1}$ Using data from the GSEOP and employing fixed-effect regressions to assess adaptation, Di Tella et al. (2005) conclude that they "cannot reject the null hypothesis that people adapt totally to income after four years".
} 
each other, including shocks to the employment of an individual (fired/promoted), to their family life (births/deaths/divorce), and to their physical person (crime/health).

The paper aims to draw out the policy implications of this strand of the happiness literature by assigning monetary values to life events. One important reason to do this is that it is often the case that life events are caused by the actions of outside agents. For instance, government decisions can force individuals to move. Also, policy decisions are often undertaken on the basis of trade-offs between the monetary costs of policy and their benefit to life satisfaction, for example in the area of health provision. Individuals can also incur life shocks due to the actions of non-government agents, such as when they are a victim of crime or when their partner dies in a car accident or due to medical negligence. In all such cases, it is an important task to assign a monetary value to a life event in order to decide on the correct level of monetary compensation or on the optimal decision in the case of trade-offs.

There is already a large empirical literature on the valuation of unpriced goods, such as life events, with studies traditionally using either hedonic price methods or contingent valuation methods. The hedonic price method determines a value for a life event by estimating the effect that its occurrence has on the market value of a related good. For example, Gibbons (2004) valuates crime by estimating the impact that crime has on property prices. The hedonic price method has been used to value injury (Hersch, 1998), illness (Sandy and Elliot, 2005), and changes in climate (Maddison and Bigano, 2003; Rehdanz, 2006), amongst many other applications. The contingent valuation method uses surveys to calculate the amount of money an individual is willing to pay or willing to accept for a change in circumstances. ${ }^{2}$ This approach is most often used to valuate environmental and health policies (Hanemann, 1994; Diener et al., 1998).

We add to the monetary valuation literature by introducing a new method for calculating compensations. Fundamentally, this new method involves a comparison between the Discounted Life Satisfaction (DLS) of a life event (e.g. death of spouse), which incorporates both anticipation and adaptation effects, with the DLS of a positive financial shock (e.g. winning the lottery). A big advantage of this approach is that it by-passes the well-known difficulties of correctly estimating the importance of income for life satisfaction (see Clark et al., 2008, for a summary of these difficulties). We contrast this new approach with the most standard approach in the happiness literature for calculating compensations, which simply estimates life satisfaction regressions that include life events and income, and then calculates the trade-off between the satisfaction effect of income and the satisfaction effect of the life event. This is the approach that has been taken in studies evaluating disease (Ferrer-iCarbonell and Van Praag, 2002; Groot et al., 2004), airport noise (Van Praag and Baarsma, 2005), informal care (Van Den Berg and Ferrer-i-Carbonell, 2007), bereavement (Oswald and Powdthavee, 2008), droughts (Carroll et al., 2008) and social networks (Powdthavee, 2008). A key finding is that our approach generates much lower shadow values of life-events than the traditional approach, because it takes into account the fact that compensation has more than a momentary effect on life satisfaction.

\footnotetext{
${ }^{2}$ For discussions of contingent valuation, see Hausman (1993) and Carson et al. (2001).
} 


\section{Data}

We use the first six waves of the Household, Income and Labour Dynamics in Australia (HILDA) survey. HILDA is a household-based longitudinal study that began in 2001 with 7,682 households and 19,914 individuals, and the latest data release is for 2006. The survey is nationally-representative with the exception of under-sampling individuals living in more remote areas of Australia. Each year since 2001, interviews have been conducted with all members of each household who are at least fifteen years old at the time of the interview. In these interviews, information is collected on labour force dynamics, education, income, family formation, health and other specialised topics. ${ }^{3}$

Life satisfaction is measured in HILDA annually using the response to the familiar question:

"All things considered, how satisfied are you with your life?".

Respondents are told to:

"Pick a number between 0 and 10 to indicate how satisfied you are" and that "the more satisfied you are, the higher the number you should pick".

The median and modal response to this question equals 8 , and the distribution of responses is negatively skewed, with over three quarters choosing 7 or above.

The occurrence of life events are determined by responses in a section of HILDA's selfcompletion questionnaire included in waves 2 to 6 . Respondents are told:

"We now would like you to think about major events that have happened in your life over the past 12 months. For each statement cross the YES box or the NO box to indicate whether each event happened during the past 12 months. If you answer "YES", then also cross one box to indicate how long ago the event happened or started". This information is given by quarter.

Respondents are given 16 statements to evaluate; however, in this paper, we concentrate on the following 10 substantive life events:

1. Got married;

2. Separated from spouse or long-term partner;

3. Partner or I gave birth to, or adopted, a child;

4. Serious personal injury or illness to self;

5. Death of spouse or child; ${ }^{4}$

\footnotetext{
${ }^{3}$ HILDA is described in more detail in Watson and Wooden (2004).

${ }^{4}$ The survey does not distinguish between the death of a spouse and the death of a child. However, as child mortality is a rare event in contemporary Australia, we expect the majority of these observations are death of spouse.
} 
6. Victim of a property crime (e.g. theft, housebreaking);

7. Fired or made redundant by an employer;

8. Major improvement in financial situation (e.g. won lottery, received an inheritance);

9. Major worsening in financial situation (e.g. went bankrupt);

10. Change of residence.

The numbers of instances each life event occurs within our sample are displayed in the first column of Table 1. For each of these events we have a non-trivial number of occurrences, with changing residence the most common event, and death of spouse or child the least prevalent event. Column 2 displays the mean number of life events experienced, conditional on having experienced a life event. For example, those individuals that have a major improvement in finances, experience on average 3.56 life events (including the financial improvement) within our panel time-frame. These figures range from 3.38 to 4.83 , and demonstrate that individuals who experience one life event are likely to experience several others. The final five columns display the mean characteristics of individuals, conditional on having experienced a life event. They show that different types of individuals experience different types of life events, which makes it important to account for selection effects in our empirical models.

For our empirical analysis, dummy variables are created that represent the number of quarters prior to the first occurrence of a life event and the number of quarters after the last occurrence of a life event. Given the length of our panel we focus in this paper on eight quarters before and after the life event, which can be expanded as additional waves of HILDA are released. ${ }^{5}$

\section{Selection, Anticipation and Adaptation Effects}

When considering the various determinants of life satisfaction, we have the following estimation equations in mind:

$$
\begin{aligned}
L S_{i t} & =Z_{i}^{\prime} \alpha^{*}+\sum_{s=t-T_{1}}^{t+T_{2}} X_{i s}^{\prime} \beta_{s}^{*}+u_{i t}^{*} \\
& =Z_{i}^{\prime} \alpha^{*}+\sum_{s=t+1}^{t+T_{2}} X_{i s}^{\prime} \beta_{s}^{*}+X_{i t}^{\prime} \beta_{t}^{*}+\sum_{s=t-T_{1}}^{t-1} X_{i s}^{\prime} \beta_{s}^{*}+u_{i t}^{*}
\end{aligned}
$$

\footnotetext{
${ }^{5}$ This approach allows us to include individuals who have experienced the same type of shock more than once. For example, within the span of our sample some individuals experience a major improvement in finances twice. An alternative approach for dealing with the second occurrence is to omit individuals from the sample once the second improvement occurs. This is effectively the approach taken by Clark, Diener et al. (2008). Instead, we estimate anticipation effects by examining life satisfaction prior to the first improvement and estimate adaptation effects by examining life satisfaction after the second improvement. We prefer this approach because it allows larger sample sizes; it effectively presumes that when the second shock occurs the adaptation to the first shock becomes complete.
} 
and

$$
\begin{aligned}
L S_{i t} & =\sum_{s=t-T_{1}}^{t+T_{2}} X_{i s}^{\prime} \beta_{s}+v_{i}+u_{i t} \\
& =\sum_{s=t+1}^{t+T_{2}} X_{i s}^{\prime} \beta_{s}+X_{i t}^{\prime} \beta_{t}+\sum_{s=t-T_{1}}^{t-1} X_{i s}^{\prime} \beta_{s}+v_{i}+u_{i t}
\end{aligned}
$$

where $L S_{i t}$ is the life satisfaction of person $i$ in period $t ; Z_{i}$ is a vector of fixed individual characteristics, such as gender and education; $X_{i s}$ denotes a vector of life events that occur at time $s ; u_{i t}$ is iid noise; and $v_{i}$ is a fixed individual effect. The time periods $s$ run in quarters. Hence the term $\sum_{s=t+T_{1}}^{t+T_{2}} X_{i s}^{\prime} \beta_{s}$ contains life events that will occur in future quarters; $X_{i t}^{\prime} \beta_{t}$ contains the events occurring in the quarter before the interview (i.e. anywhere in the last 3 months); and $\sum_{s=t-T_{1}}^{t-1} X_{i s}^{\prime} \beta_{s}$ contains events that occurred in quarters preceding the current one.

In the second equation, one of the $\beta_{s}$ has to be fixed because they are not all simultaneously identified. We take $\beta_{t+T_{2}}=0$ as the natural normalisation (i.e. $T_{2}$ is so far into the future that we define it as having no effect on the present).

The difference between the first and the second equation is the individual fixed effect $v_{i}$ which is only included in the second equation. The second equation is therefore more general than the first. In our empirical analyses, we will exploit the difference between the two equations in order to get at the question of the selectivity of the events. With these two equations in mind, we can define the following items of interest:

1. The anticipation effect of a life event. When we think of anticipation effects, we think of the importance of an event for life satisfaction before it actually occurs i.e. the effect of having an event happening in the future. We can then formally define the total amount of anticipation as $\beta_{t+1}-\beta_{t+T_{2}}$, which is hence the effect of the event in the quarter before it happens minus the effect of an event in the far future. The anticipation path is given by $\left\{\beta_{t+T_{2}}, \beta_{t+T_{2}-1}, \ldots, \beta_{t+1}\right\}$.

2. The adaptation effect after a life event. When we think of adaptation effects, we think of the decline in the satisfaction effect over time after the event has occurred. If we see the 'full' effect of an event as the importance of the event in the period it happens, i.e. $\beta_{t}$, and if we see the long-run effect of an event as the effect still remaining long after it occurred, i.e. $\beta_{t-T_{1}}$, then we can define the adaptation effect after an event as $\beta_{t-T_{1}}-\beta_{t}$. The adaptation path is given by $\left\{\beta_{t}, \beta_{t-1}, \ldots, \beta_{t-T_{1}}\right\}$.

3. The selection effect of a life event. Here we think of the happiness characteristics of the type of person prone to experience a life event, reflecting the idea that such events do not happen randomly across the population but that some individuals are more prone to them than others. We can find this degree of selectivity by comparing the effect of an event a long time before it occurs for the equation without fixed effects versus 
the equation with fixed effects, i.e. we can define the selection effect as $\beta_{t+T_{2}}^{*}-\beta_{t+T_{2}}$. Note that this is the same as the average of the $v_{i}$ for all those who are subject to the event, corrected for the known fixed factors $Z_{i}$. The interpretation of the selection effect is that it captures the average unobserved fixed characteristics of people who are subject to a specific event.

\section{Estimation Results}

The matrix of estimated fixed effect coefficients $\left\{\hat{\beta}_{t+T_{2}}, \hat{\beta}_{t+T_{2}-1}, \ldots, \hat{\beta}_{t-T_{1}}\right\}$ are shown in Table 2 and the matrix of estimated OLS coefficients $\left\{\hat{\beta}_{t+T_{2}}^{*}, \hat{\beta}_{t+T_{2}-1}^{*}, \ldots, \hat{\beta}_{t-T_{1}}^{*}\right\}$ are shown in Table 3. These tables have a large number of coefficients, so for ease of interpretation we have also produced smoothed graphs of the coefficients in Figures 1,2 and 3. Each graph has two lines. The dashed line shows the coefficients from the fixed-effects model and the solid line shows the coefficients from the OLS model. The difference between these lines represents the selection effect. Furthermore, the pathway of the dashed lines before the quarter of the event is the anticipation profile and the pathway after the quarter of the life event is the adaptation profile.

The Tables and Figures show that the coefficients of the fixed effects estimates are generally lower than the OLS estimates for negative events and generally higher for positive events. This is clear evidence of a significant degree of selection: bad things happen to those already unhappy and good things to those already happy. The magnitude and statistical significance of these selection effects are shown in the first column of Table 4. Selection effects are significant for the life events: worsening in finances, death of spouse/child, fired and separation. These results confirm the wide-spread belief in the literature that reverse causality is pervasive in life satisfaction (see Ferrer and Frijters, 2004), and imply that cross-sections are uninformative about the effect of life events.

The results also reveal strong anticipation effects. For negative life events the anticipation profile is always negative and for positive life events it is always positive. The largest effects exist for birth and worsening in finances: life satisfaction is on average 0.321 higher before a birth occurs, while life satisfaction is on average 0.208 lower before a worsening in finances (see column 2 in Table 4). Naturally, a birth is a highly predictable event and individuals can presumably see a bankruptcy coming for a long time. Thus, our results provide evidence that individuals do actively anticipate good and bad events. This in turn implies that regressions based on the effect of a life event in the year of occurrence (which implicitly defines the effect as the change in life satisfaction between last year and this year) would grossly underestimate the importance of life events.

The events with the strongest momentary impact i.e. $\beta_{t}$, are the worsening of finances $(-0.546)$, death of a spouse/child (-0.567), and marriage/separation (0.428 versus -0.493$)$. Importantly, however, we see for all life events that adaptation dissipates this momentary effect - for all life events the effect of an event 2 years afterwards is lower than the momentary effect. Moreover, for most events the effect after 2 years is about zero. Adaptation is most 
strongly significant for marriage, separation, death of spouse/child and worsening in finances (see column 4 in Table 4). ${ }^{6}$ Thus, it seems that individuals get over most major life events, although our data of course does not enable us to identify the actual mechanisms individuals use to overcome these life changes. It might well be the case for instance that individuals get over separation by finding a new partner.

Another striking aspect of the results is that there is clear evidence of asymmetry with regards to financial shocks: negative financial shocks are seen as about twice as bad as financial improvements are good. Also with regards to life itself there is an asymmetry: a birth of a new individual has a positive effect ( 0.241 in the first quarter) that is less than a half of the absolute effect of the death of a spouse/child (-0.567 in the first quarter). This has an immediate policy implication: unlike what naive utilitarianism would imply, it is not the case that one death and one birth cancel each other out in terms of effect on total social welfare. Preventing deaths is worth more than stimulating births. Interestingly, there is no apparent asymmetry between the good and bad events related to relationships: the positive effect of marriage is of the same order of magnitude as the negative effect of separation.

\section{$5 \quad$ Valuing Life Events}

\subsection{The Dynamic Problem and Two Solutions}

In this section we estimate the income required to compensate for the occurrence of certain life events. The studies we reviewed in the introduction use either revealed preference methods or direct stated preference methods to estimate the compensating income. Our method is based on estimating the amount of income an individual should receive after the occurrence of a life event, such that their discounted life satisfaction with the compensation is equivalent to the discounted life satisfaction if the life event did not occur. We have the following programming problem:

$$
\sum_{s=0}^{T_{i}}(1-\rho)^{s-t} L S_{i t}(\text { no life event })=\sum_{s=0}^{T}(1-\rho)^{s-t} L S_{i t}(\text { life event \& compensation })
$$

with $\rho$ a discount rate for future years, $t$ the period in which the life event takes place, and $T_{i}-t$ the number of years that individual $i$ still has to live.

There are many different compensation schemes that would solve this programming problem. We focus on schemes in which the individual receives compensation starting in the same period that the life event occurs. In other words, if an individual has a life event in period $t$, we ask how much additional income they must be given as a one-off or permanently in order to have the same discounted happiness as someone to whom the life event did not occur, where discounted life satisfaction includes both adaptation and anticipation effects.

\footnotetext{
${ }^{6}$ Similarly, Kuhn et al. (2008) found that any happiness gain from winning money from the Dutch Postcode Lottery was gone after 8 months.
} 
To determine the amount of compensating income we use two different approaches, which we describe and contrast briefly before giving a full account in the following subsection. In the first approach, we compare the discounted life satisfaction $(D L S)$ effects from the life event 'major improvement in finances', with the discounted life satisfaction effects from the life events we wish to value (such as 'death of spouse or child'). What we then essentially do is look at how many 'major improvements in finances' are necessary to off-set another life-change, after which we put a monetary figure on how much money is involved with a 'major improvement in finances' and therefore with all other life-events.

The second basic approach views income changes as separate from life events. Thus, the models are re-estimated with income as a separate variable and then the trade-offs are calculated. The second approach is more standard but has two major drawbacks. One is that income is seen as something separate from life-events, i.e. its changes are not itself subject to anticipation and adaptation. A more important and fundamental problem with looking at the coefficient on income is that it is hard to identify. Observed changes in income, which are in the data often driven by changes in life circumstances (moving, separating, being promoted, changes in the amount of subsidies and welfare received due to changes in family composition) are then all treated as one homogenous change in income. Additionally to this, it is the case that the timing of income changes is not very precise in the data (including our data), and that from a theoretical point of view one would want to measure consumption rather than income. All these problems can be seen as a form of measurement error in income changes, leading us to expect that income coefficients are under-estimated in life-satisfaction regressions, which in turn makes us expect the compensating income to be much greater in the second approach than in the first approach.

\subsection{Discounted Life Satisfaction}

We now describe the first approach in greater detail. The ratio of life satisfaction effects discounted back to 8 quarters before the period $t$ event (so that anticipation effects are captured) equals:

$\frac{D L S \text { (life event) }}{D L S \text { (finance improvement) }}=\frac{(1-\rho) \beta_{t+7}+\ldots+(1-\rho)^{14} \beta_{t-7}+(1-\rho)^{15} \frac{\left(1-(1-\rho)^{T_{i}-t-8}\right) \beta_{t-8}}{\rho}}{(1-\rho) \alpha_{t+7}+\ldots+(1-\rho)^{14} \alpha_{t-7}+(1-\rho)^{15} \frac{\left(1-(1-\rho)^{T_{i}-t-8}\right) \alpha_{t-8}}{\rho}}$

where $\left\{\alpha_{t+7}, \alpha_{t+6}, \ldots, \alpha_{t-8}\right\}$ are the life satisfaction effects from a 'major improvement in finances' and $\left\{\beta_{t+7}, \beta_{t+6}, \ldots, \beta_{t-8}\right\}$ are the life satisfaction effects from the life event under evaluation. The last terms of the denominator and the numerator capture the effect of the life events and the compensation scheme on the 'rest of life', which presumes that $\beta_{t-8}$ and $\alpha_{t-8}$ reflect persistent effects. The estimated life satisfaction effects come from the fixed effect regression specified in equation 2 and are reported in Table 2. We do the calculations both for an annual discount rate $\rho$ of 5 percent and of 10 per cent.

To convert these DLS ratios to dollar values we require an estimate of the income change that corresponds to the reporting of a 'major improvement in finances'. Individuals will have different reasons for reporting a financial improvement, some of which may not even 
correspond to an increase in income, and some corresponding to income increases spread out over many years. We estimate the income gain by using the mean windfall income change of individuals who report a financial improvement and a positive windfall income. This corresponds to 594 observations out of the 1368 observations reporting positive improvements in finances. Windfall income consists of inheritance, bequests, redundancy/severance payments, parental transfers, payments from non-household members and other irregular sources of payments. Receipt of a windfall income is an important reason why many individuals report a financial improvement: the proportion of such individuals reporting a positive windfall income equals 0.43 , whereas the proportion of all other individuals reporting a positive windfall income equals 0.14 . This mean value of the windfall income is about $\$ 120,000$ AUS, or about $\$ 100,000$ US.

The second approach we take can be described as the 'classic' approach to valuating any amenity by means of stated preferences. In the second approach used to determine the amount of compensating income, we estimate the following regression:

$$
L S_{i t}=\delta y_{i t}+\sum_{s=t-T_{1}}^{t+T_{2}} X_{i s}^{\prime} \beta_{s}+v_{i}+u_{i t}
$$

where $y_{i t}$ equals the log annual household income of individual $i$ in period $t$, and all other terms are defined as above. The estimated log household income coefficient from this model equals 0.056 and has a standard deviation of 0.010. In this specification, the effect of a permanent income shock on life satisfaction equals $\delta$ in all periods following the shock. Therefore, the permanent log income change $\Delta y$ required to compensate for the life event equals:

$$
\Delta y=\frac{(1-\rho) \beta_{t+7}+\ldots+(1-\rho)^{14} \beta_{t-7}+(1-\rho)^{15} \frac{\left(1-(1-\rho)^{T_{i}-t-8}\right) \beta_{t-8}}{\rho}}{(1-\rho)^{8} \frac{\left(1-(1-\rho)^{T_{i}-t}\right) \delta}{\rho}}
$$

The absolute value of the income change will depend on the individual's initial income level, with wealthier individuals receiving higher absolute compensation. For this reason we present compensating income values for mean household income and median household income.

\subsection{Valuation Results}

The results for two compensation methodologies are reported in Table 5, where the top half relates to a discount rate of $5 \%$ and the bottom half to a discount rate of $10 \%{ }^{7}$ The first column in the top half shows the $D L S$ ratios of each event relative to that of an improvement in finances. The largest $D L S$ ratio is for the life event 'death of a spouse or child' and equals 1.56. This estimate indicates that the negative discounted life satisfaction

\footnotetext{
${ }^{7}$ For all events where there was no significant long-run effect we presumed these to be zero outside the time-period of the sample (more than 8 periods).
} 
effect from the death of a spouse or child is 1.56 times larger than the positive discounted life satisfaction effect from a major improvement in finances.

The second column of Table 5 shows the one-off windfall needed to compensate for the life event under consideration. This one-off windfall is negative for positive events and positive for negative events. Since the mean value of a windfall-related positive improvement in finances is about $\$ 120,000$ Australian dollars (roughly $\$ 100,000$ US $\$$ ), the value of each non-financial event is the DLS ratio times this value. This is highest for the death of a spouse/child $(\$ 178,000)$ and lowest for being fired, which only has an equivalent effect of $\$ 6,000 .^{8}$ One of the reasons for this low value is that the effect of being fired is now net of any other associated life shock, such as a fall in income: it is the pure 'emotional cost' of being fired.

The compensatory income needed for marriage and birth are negative, because they are positive events, and are both worth around $\$ 17,000$. Somewhat surprisingly, the most positive event is moving, worth around $\$ 53,000$. The majority of this effect is long-run due to the fact that the effect of moving does not seem to wear of in our sample period. Even though the short-run effect of moving is quite low, its discounted long-run effect is very high.

The third and fourth column contrast these values with the discounted value of the permanent change in income needed using the classic valuation method, evaluated at the mean and median income. These values are much larger i.e. in the order of 3 times as large: the death of a spouse/child is equivalent to a loss of about $\$ 411,000$, and birth of a child is worth the equivalent of a windfall gain of $\$ 319,000$. Since these results come from different regressions, we also see slight changes in the relative monetary values, such as the effect of being fired rising compared to the specifications that did not estimate income effects but did contain negative and positive financial effects, which is the endogeneity problem signalled before. We also obtain the usual finding that compensation needed at the mean income is higher than at the median income because mean incomes are higher than median incomes.

If we now look at what adopting a $10 \%$ discount rate gives, we see that the general picture is much the same. Higher discounting makes anticipation effects relatively more important and adaptation effects less important, which especially increases the relative importance of marriage and birth which are strongly anticipated. The absolute DLS ratio of marriage rises from 0.15 to 0.23 and that of birth from 0.17 to 0.25 . The compensations needed are slightly higher than with $5 \%$ discount rates, mainly because the low degree to which financial improvements lead to anticipatory joy.

Therefore, as expected, we see that the income compensation needed is far greater under this second, more standard, approach. We attribute this to identification issues with the coefficient in income arising from the fact that income changes captures an amalgam of life changes each with different effects, and with unknown timing, leading to classic downward

\footnotetext{
${ }^{8}$ Interestingly, Blanchflower and Oswald (2004) find using the classic approach that a lasting marriage, compared with widowhood, is worth around $\$ 100,000$ per year. If such compensation was paid only until complete adaptation (i.e. $\$ 100,000$ for 2 to 3 years) rather than for life, then the total compensation value would be similar to our estimated death of spouse compensation value.
} 
bias in the income coefficient due to measurement error.

\section{Conclusions}

In this paper we have addressed the questions of when and to what degree individuals are affected by positive and negative life events using six waves of data from the Household, Income and Labour Dynamics in Australia (HILDA) survey. The key advantage of this panel survey over others that are most widely used in the life satisfaction literature is that it directly collects extensive information from respondents about major life events that they have experienced over the last 12 months. Importantly we are able to improve on previous studies of adaptation because the data also enables us to time these events at quarterly intervals rather than simply having to rely on observed year-on-year changes in respondents circumstances. This is particularly important if individuals fully adapt to some life events within a year.

We have focused on a wide range of life events, including financial, marital and workrelated, but we have been particularly interested in establishing the impact of the deaths of very close family members (partner or child) and being a victim of crime. We have traced the impact of these events on life satisfaction before they actually occurred and labelled this the 'anticipation effect'. We have estimated the adaptation to the events after they occur which we have labelled the 'adaptation effect'. We also compared the life satisfaction of those subjected to a major life with those who did not experience it, a difference we have labelled as the 'selection effect'. Importantly, we found strong robust evidence for significant adaptation, anticipation and selection effects, which has two important methodological implications: It means (1) that using cross-sectional data we would not be able to establish the importance of life events because such data cannot identify selection effects; (2) that studies using aggregated measures of lags and leads (such as yearly lags and leads) will miss much of the action in terms of adaptation and anticipation and will substantially under-estimate the full effect of a life event.

The events of greatest importance in terms of life satisfaction are found to be the death of a spouse or child, and separation, but we also find an important effect of negative financial events. Deterioration in the financial situation has a far greater impact on life satisfaction than a positive financial event, and individuals appear to adapt more slowly to negative events. Apart from the death of a close relative and changes in housing, individuals were found to fully adapt to all life events after 2 years. In comparison, individuals adapt only about $75 \%$ to the death of a close relative. Further waves of the data when released will allow us to extend the profiles of the adaptation path of this most dramatic of life events, which is important for calculating compensation.

Finally, we have introduced a new method of valuing life events by comparing them not directly to an income coefficient, but rather to positive financial changes, such as lottery wins and bequests. We essentially calculated how much any life event was worth in terms of these 'windfalls' and how much a windfall meant in terms of money. This approach, coupled with the consideration made for anticipation and adaptation effects, gave much 
lower amounts of required compensation than the standard approach. 


\section{References}

Blanchflower, D.G. and Oswald, A.J. (2004). Well-being over time in Britain and the USA. Journal of Public Economics, vol. 88, pp. 1359-1386.

Carroll, N, Frijters, P., and M. A. Shields (2008). Quantifying the Costs of Drought: New Evidence from Life Satisfaction Data. Forthcoming Journal of Population Economics.

Carson, R., Flores, N. and Meade, N. (2001). Contingent valuation: controversies and evidence. Environmental and Resource Economics, vol. 19, pp. 173-210.

Clark, A. (2006). A note on unhappiness and unemployment duration. Applied Economics Quarterly, vol. 52, pp. 291-308.

Clark, A., Frijters, P. and Shields, MA. (2008). Relative income, happiness and utility: An explanation for the Easterlin Paradox and other puzzles. Journal of Economic Literature, vol. 46, pp.95-144.

Clark, A, Diener, E., Georgellis, Y. and Lucas, R. (2008). Lags and leads in life satisfaction: A test of the baseline hypothesis. Economic Journal, vol. 118, pp. F222-F239.

Diener, A., O'Brien, B. and Gafni, A. (1998). Health care contingent valuation studies: a review and classification of the literature. Health Economics, vol. 7, pp. 313-326.

Di Tella, R., Haisken-DeNew, J. and Macculloch, R. (2005). Happiness adaptation to income and to status in an individual panel. Working Paper, Harvard Business School.

Dolan, P. and Kahneman, D. (2008). Interpetations of utility and their implications for the valuation of health. Economic Journal, vol. 118, pp.

Ferrer-i-Carbonell, A. and van Praag, B. (2002). The subjective costs of health losses due to chronic diseases: An alternative model for monetary appraisal. Health Economics, vol. 11, pp. 709-722.

Ferrer-i-Carbonel, A. and Frijters, P. (2004). The effect of metholodogy on the determinants of happiness. Economic Journal, vol. 114, pp. 641-659.

Gibbons, S. (2004). The costs of urban property crime. Economic Journal, vol. 114, pp. F441-F463.

Graham, L. and Oswald, A. (2005). Hedonic capital. Working paper, University College London.

Groot, W., van den Brink, H. and Plug, E. (2004). Money for health: The equivalent variation of cardiovascular diseases. Health Economics, vol. 13, pp. 859-872.

Hanemann, W. (1994). Valuing the environment through contingent valuation. Joumal of Economic Perspectives, vol. 8, pp. 19-43. 
Hersch, J. (1998). Compensating differentials for gender-specific job injury risks. American Economic Review, vol. 88, pp. 598-607.

Kuhn, P., Kooreman, P., Soetevent, A. and Kapteyn, A. (2008). The own and social effects of an unexpected income shock: Evidence from the Dutch Postcode Lottery. NBER Working Paper no. W14035.

Lucas, R. and Clark, A. (2006). Do people really adapt to marriage? Journal of Happiness Studies, vol. 7, pp. 405-426.

Lucas, R., Clarke, A., Georgellis, Y. and Diener, E. (2004). Unemployment alters the setpoint for life satisfaction. Psychological Science, vol. 15, pp. 8-13.

Maddison, D. and Bigano, A. (2003). The amenity value of the Italian climate. Journal of Environmental Economics and Management, vol. 45, pp. 319-332.

Menzel, P., Dolan, P., Richardson, J. and Olsen, J. (2002). The role of adaptation to disability and disease in health state valuation: A preliminary normative analysis. Social Science and Medicine, vol. 55, pp, 2149-2158.

Oswald, A. and Powdthavee, N. (2008). Does happiness adapt? A longitudinal study of disability with implications for economists and judges. Journal of Public Economics, vol. 92, pp. 1061-1077.

Oswald, A and Gardner, J. (2006). Do Divorcing Couples Become Happier By Breaking Up?' Journal of the Royal Statistical Society Series A, vol. 169, pp. 319-336.

Oswald, A. and Powdthavee, N. (2008). Death, happiness, and the calculation of compensatory damages. Forthcoming Journal of Legal Studies.

Powdthavee, N. (2008). Putting a price tag on friends, relatives and neighbours: Using surveys of life satisfaction to value social relationships. Forthcoming Journal of SocioEconomics.

Rayo, L. and Becker, G. (2007). Evolutionary efficiency and happiness. Journal of Political Economy, vol. 115, pp. 302-337.

Rehdanz, K. (2006). Hedonic pricing of climate change impacts to households in Great Britain. Climatic Change, vol. 74, pp. 413-434.

Sandy, R. and Elliott, R. (2005). Long-term illness and wages: The impact of the risk of occupationally related long-term illness on earnings. Journal of Human Resources, vol. 40, pp. 744-768.

Watson, N. and M. Wooden. (2004). The HILDA Survey Four Years On. Australian Economic Review, vol. 37, pp. 343-349. 
Van Den Berg, B. and Ferrer-i-Carbonell, A. (2007). Monetary valuation of informal care: The well-being valuation method', Health Economics, vol. 16, pp. 1227-1244.

Van Praag, B. and Baarsma, B. (2005). Using happiness surveys to value intangibles: The case of airport noise. Economic Journal, vol. 115, pp. 224-246.

Zimmermann, A. and Easterlin, R. (2006). Happily ever after? Cohabitation, marriage, divorce, and happiness in Germany. Population and Development Review, vol. 32, pp. 511528. 
Table 1 Descriptive Statistics by Life Events

\begin{tabular}{lccccccc}
\hline \multirow{2}{*}{ Life Events } & Number of & \multicolumn{5}{c}{ Means - Conditional on Occurrence of Life Event } \\
\cline { 3 - 7 } Occurrences & Life events & Age & Male & Income & Employed & Degree \\
\hline Finances improve & 1368 & 3.56 & 42.0 & 0.51 & 80,758 & 0.74 & 0.27 \\
Finance worsen & 1180 & 4.83 & 40.2 & 0.50 & 53,747 & 0.57 & 0.20 \\
Death of spouse/child & 346 & 3.38 & 55.5 & 0.42 & 43,315 & 0.38 & 0.11 \\
Illness & 3751 & 3.57 & 47.5 & 0.52 & 60,275 & 0.51 & 0.19 \\
Fired & 1344 & 4.15 & 35.2 & 0.61 & 68,375 & 0.65 & 0.20 \\
Marriage & 1112 & 3.85 & 35.5 & 0.50 & 76,258 & 0.79 & 0.30 \\
Birth & 1596 & 4.16 & 31.8 & 0.45 & 78,056 & 0.61 & 0.31 \\
Separation & 1817 & 4.48 & 33.8 & 0.45 & 57,703 & 0.71 & 0.17 \\
Change residence & 8105 & 3.71 & 33.6 & 0.47 & 64,622 & 0.72 & 0.24 \\
Victim of crime & 2474 & 3.86 & 38.1 & 0.52 & 72,406 & 0.72 & 0.24 \\
\hline
\end{tabular}

Note: Figures for male, employed and degree are percentages. Income is total household income in 2001 prices. 


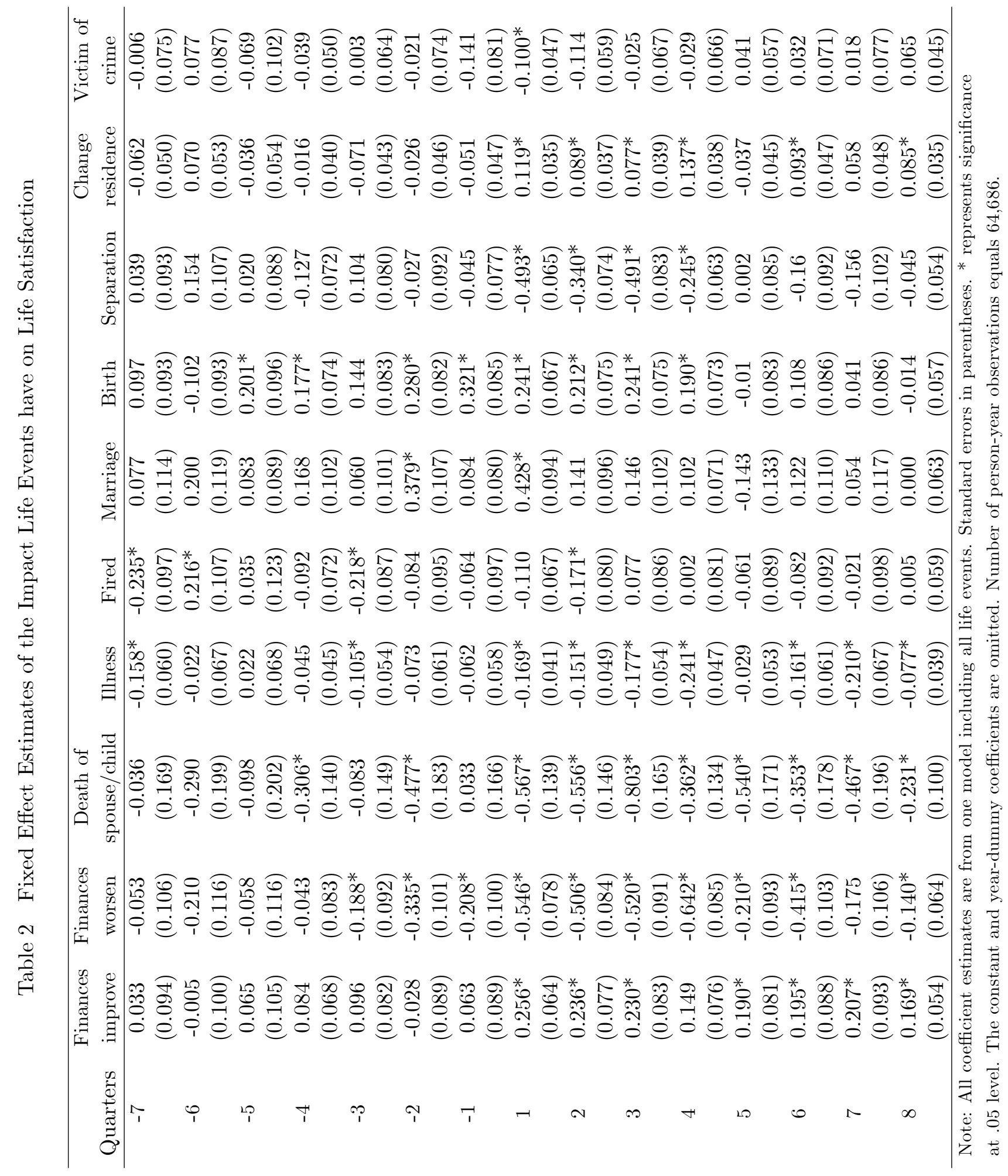




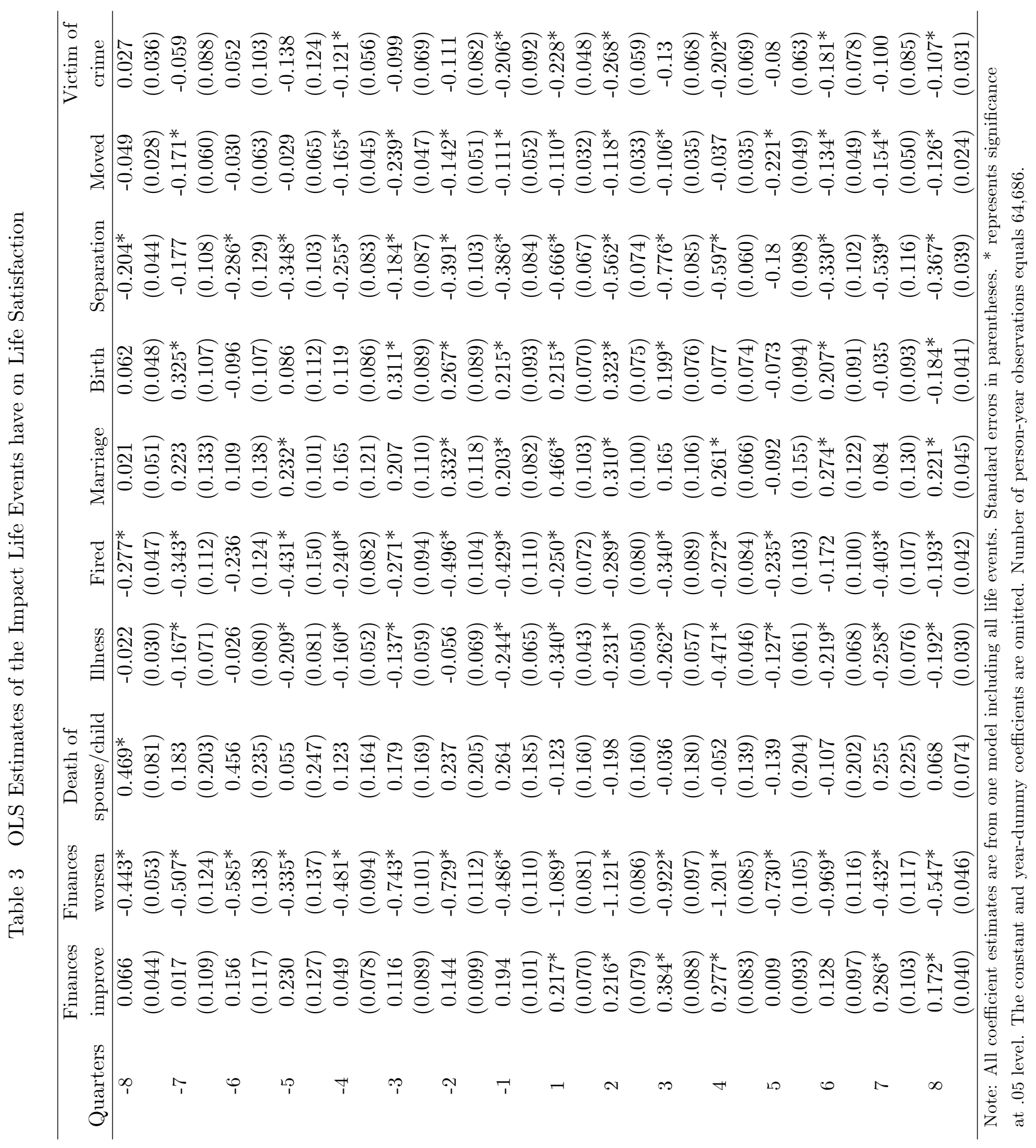


Table 4 Anticipation, Adaptation and Selection Effects

\begin{tabular}{lcccc}
\hline & Selection & Anticipation & Momentary & Adaptation \\
& $\beta_{t}$ & $\beta_{t+1}-\beta_{t+T_{2}}$ & $\beta_{t-T_{1}}-\beta_{t}$ & $\beta_{t+T_{2}}^{*}-\beta_{t+T_{2}}$ \\
\hline Finances improve & 0.066 & 0.063 & $0.256^{*}$ & -0.087 \\
Finances worsen & $-0.443^{*}$ & $-0.208^{*}$ & $-0.546^{*}$ & $0.406^{*}$ \\
Death of spouse/child & $0.469^{*}$ & 0.033 & $-0.567^{*}$ & $0.336^{*}$ \\
Illness or injury & -0.022 & -0.062 & $-0.169^{*}$ & $0.092^{*}$ \\
Fired or made redundant & $-0.277^{*}$ & -0.064 & -0.110 & 0.115 \\
Marriage & 0.021 & 0.084 & $0.428^{*}$ & $-0.428^{*}$ \\
Birth & 0.062 & $0.321^{*}$ & $0.241^{*}$ & $-0.255^{*}$ \\
Separation & $-0.204^{*}$ & -0.045 & $-0.493^{*}$ & $0.448^{*}$ \\
Moved & -0.049 & -0.051 & $0.119^{*}$ & -0.034 \\
Victim of crime & 0.027 & -0.141 & $-0.100^{*}$ & $0.165^{*}$ \\
\hline
\end{tabular}

Note: Figures used to calculate efefcts are taken directly from Tables 2 and $3 .{ }^{*}$ represents significance at .05 level

Table 5 Compensating Income Values for Life Events

\begin{tabular}{lrrrrr}
\hline & \multicolumn{2}{c}{ Income Shock } & & \multicolumn{2}{c}{ Log Income } \\
\cline { 2 - 3 } \cline { 5 - 6 } Life Event & \multicolumn{1}{c}{ DLS } & & & Value at & Value at \\
Mean & Median \\
\hline 5\% Discount Rate & & Value & & & \\
Death of spouse/child & 1.56 & 178.3 & & 411.1 & 346.9 \\
Illness & 0.52 & 59.2 & & 150.1 & 126.6 \\
Fired & 0.06 & 6.9 & & 198.8 & 167.8 \\
Marriage & -0.15 & -16.5 & & -278.3 & -234.8 \\
Birth & -0.17 & -18.3 & & -318.9 & -269.1 \\
Separation & 0.14 & 14.9 & & 335.8 & 283.3 \\
Moved & -0.46 & -53.0 & & -134.5 & -113.5 \\
Victim of crime & 0.03 & 2.7 & & 65.0 & 54.9 \\
& & & & & \\
10\% Discount Rate & & & & & \\
Death of spouse/child & 1.65 & 187.6 & & 520.6 & 439.3 \\
Illness & 0.55 & 62.2 & & 188.8 & 159.3 \\
Fired & 0.09 & 10.2 & & 209.7 & 176.9 \\
Marriage & -0.23 & -24.5 & & -300.3 & -253.4 \\
Birth & -0.25 & -26.8 & & -338.4 & -285.6 \\
Separation & 0.19 & 20.7 & & 340.9 & 287.7 \\
Moved & -0.44 & -50.8 & & -154.8 & -130.7 \\
Victim of crime & 0.04 & 4.1 & 69.4 & 58.6 \\
\hline
\end{tabular}

Note: DLS denotes discounted life satisfaction. Dollar value figures in $\$ 1,000$ units. 

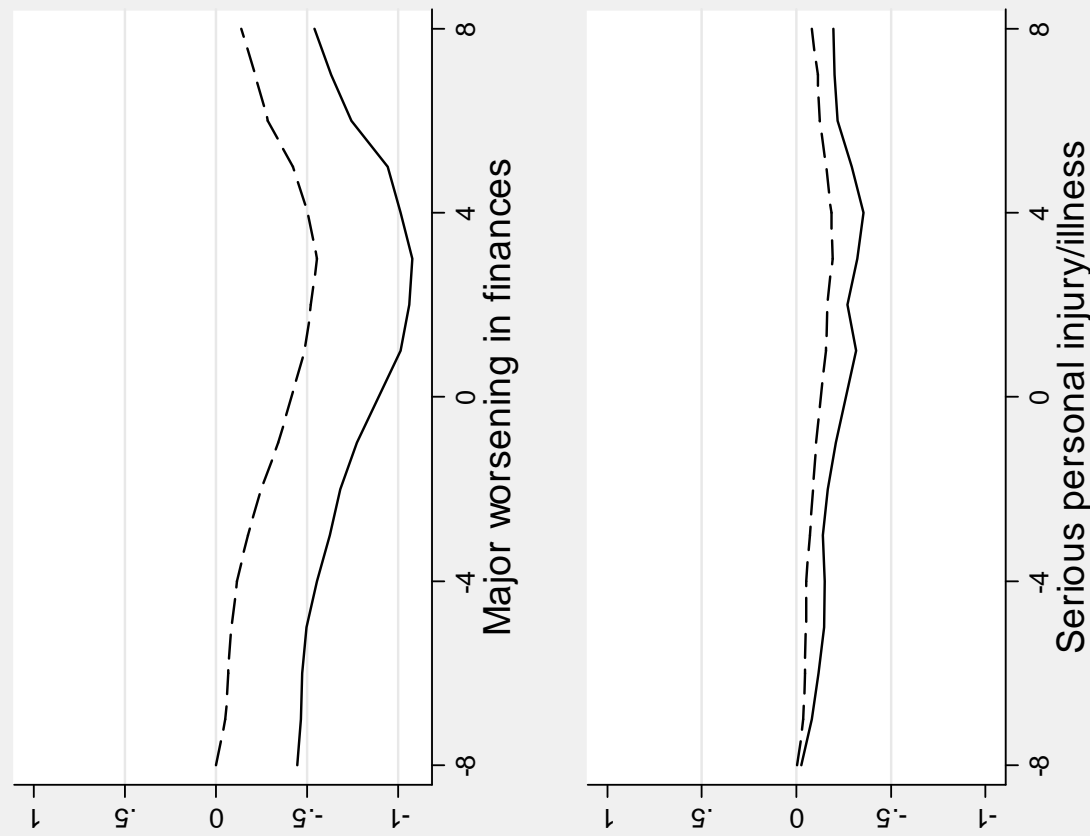

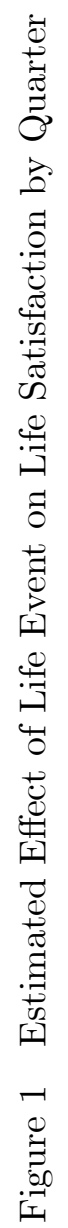
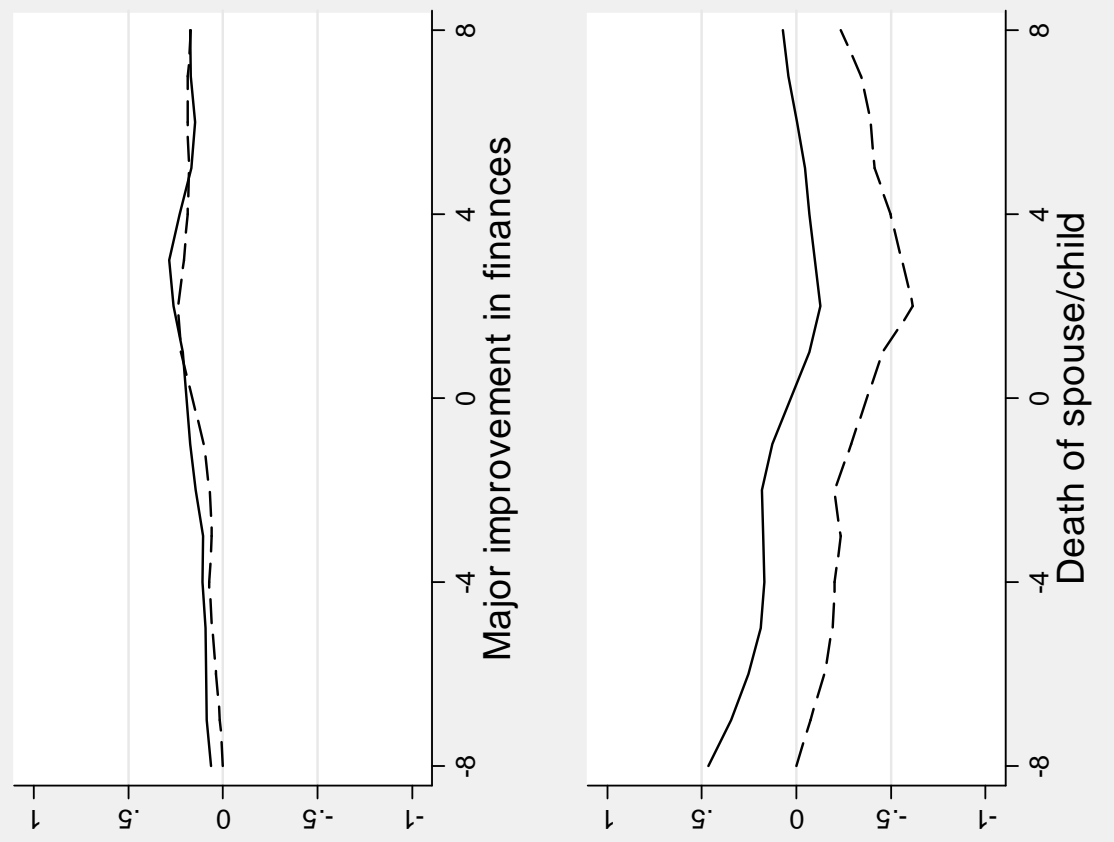

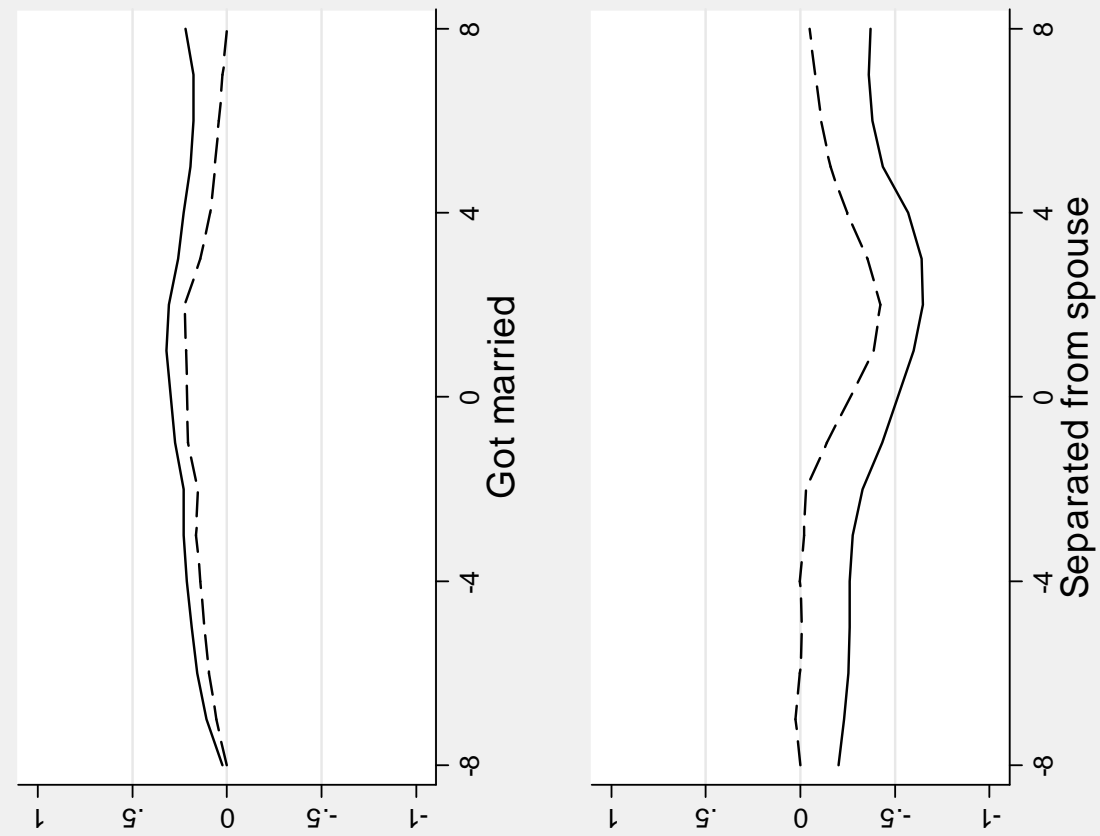

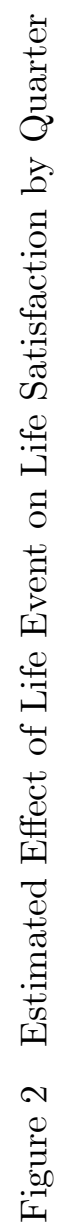
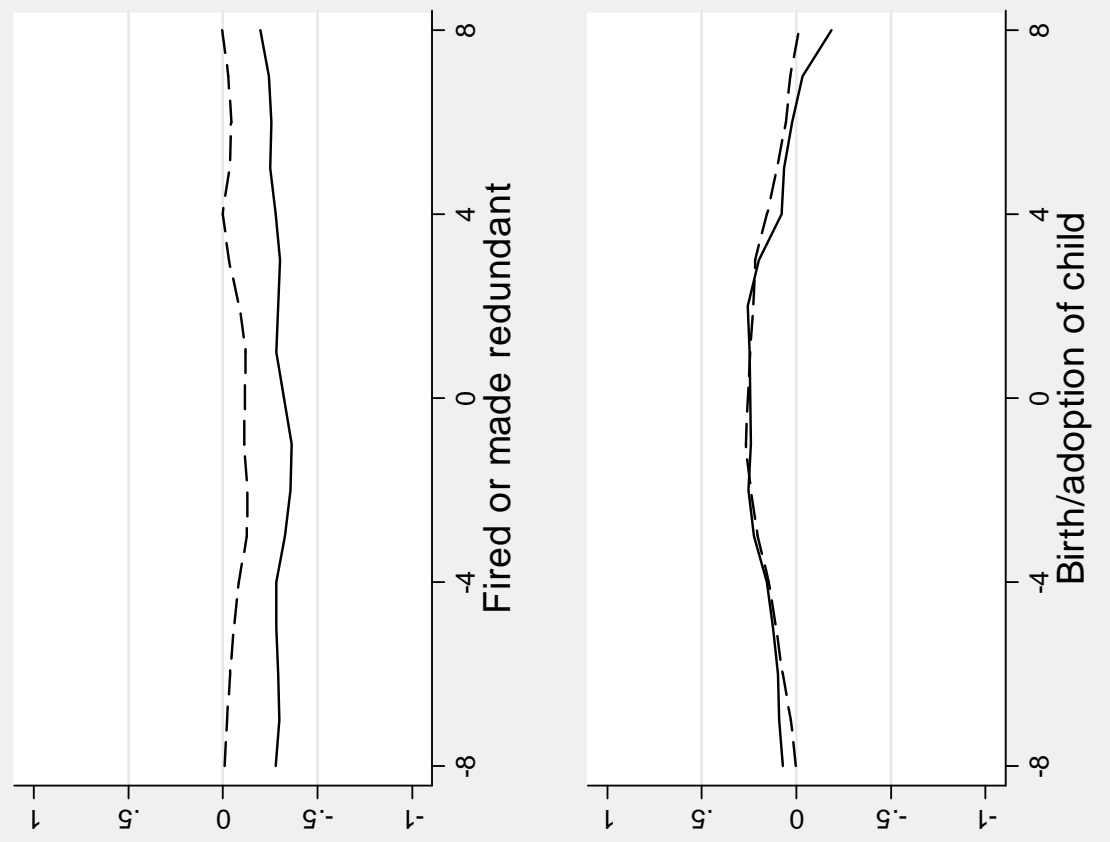

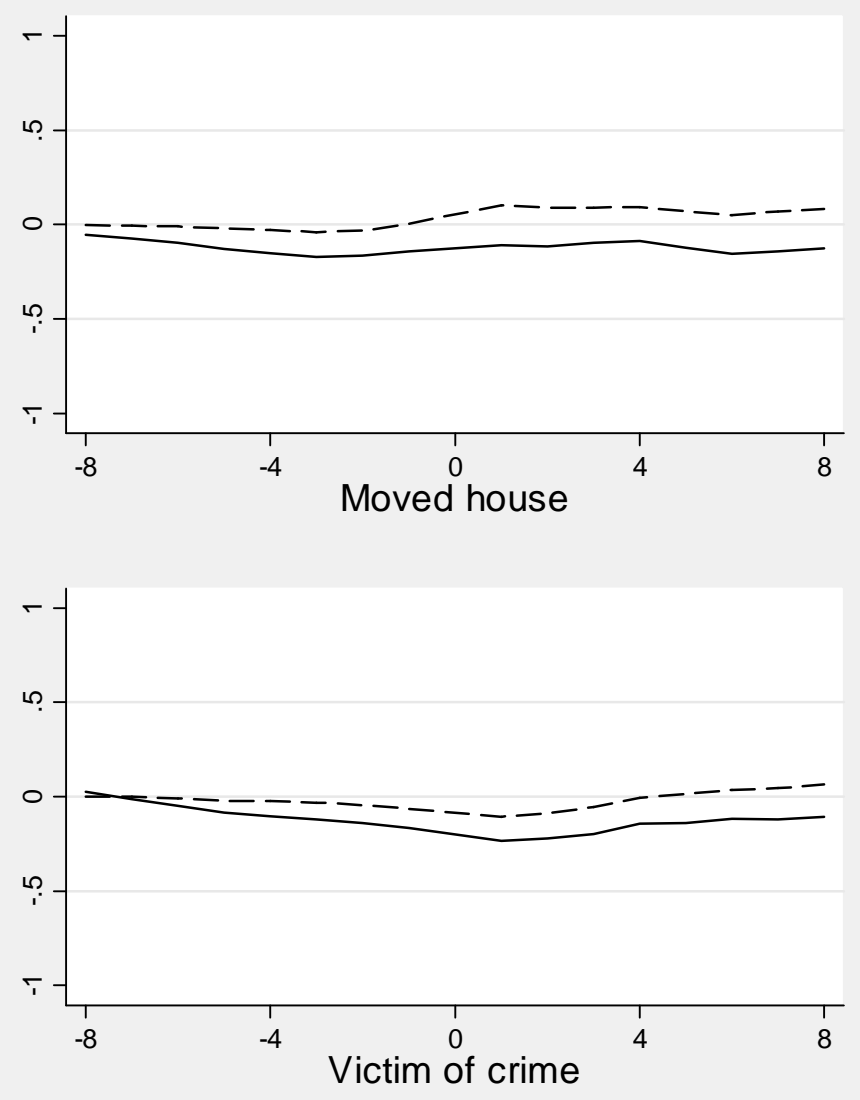

Figure 3 Estimated Effect of Life Event on Life Satisfaction by Quarter 